\title{
Introduction: Dealing with Resource Development in Canada's North
}

\author{
Chris Southcott \\ Lakehead University \& Yukon College
}

During the 1970s, southern Canada changed its perception of resource development in the Canadian North. At the beginning of the decade most observers outside of the Yukon and Northwest Territories, as well as many within the territories, saw resource development as something that was going to be of great benefit to the North (Abele, 1987; Rea, 1968). The Northern Vision that had emerged in the 1950s (Diefenbaker, 1958) continued throughout the 1960s with varying degrees of enthusiasm. While some were critical of specific government policies, the general acceptance that continued mine and oil and gas development would be important for the region was almost universal among those whose voices were most heard on the subject (Lotz, 1970). This changed in the 1970s when the voices of the Indigenous peoples of the region first started to be heard. The Berger Inquiry of that decade was probably the best known instance of people outside the region being able to hear what Indigenous communities thought about resource development in their region (Berger, 1977).

These communities told listeners that resource development had not been kind to them. Mining and the nascent oil and gas industry had been devastating to their traditional livelihoods and to their cultures. They believed that under the conditions that existed at that time, future resource development would devastate the environment that they depended upon for their survival (Berger, 1977: xi). Assaults on their cultures from European culture would increase (xvii). In terms of economic benefits,

The Northern Review 47 (2018): 3-8

Published by Yukon College, Whitehorse, Canada 
resource development would provide few long-term jobs and most of the financial benefits would flow out of the regions to southern Canada (xix). Negative social impacts would increase substantially as "alcoholism, crime, violence, and welfare dependence" would increase in Indigenous communities (xxii).

Yet Berger did not say resource development should never occur in the region-only in those instances where the people of the region, and in particular the Indigenous people of the region, could not suitably control these developments. While for environmental reasons it would not be wise to build a pipeline across northern Yukon, he stated that the Mackenzie Valley Pipeline that was the main focus of his inquiry should be "postponed for ten years" to allow time "for native claims to be settled, and for new programs and new institutions to be established"(xxvii). Throughout his report Berger notes that resource development could be helpful to northern communities if they had greater control of these developments and in so doing could ensure that more benefits stayed in the North and that negative impacts were properly mitigated.

It has been forty-one years since the initial volume of the Berger Inquiry report was published. Many of the conditions that Berger stated were necessary for resource development to be beneficial to the region appear to currently exist. Most of the region now has established modern comprehensive land claims (Alcantara, 2013; McPherson, 2003; Saku, 2002). Territorial governments now have powers increasingly close to that of provinces (Cameron \& Campbell, 2009; Dacks, 1990; Graham White, 2009). Legal institutions to assess the environmental, social, and economic impacts of development have been established (Armitage, 2005; Fitzpatrick, Sinclair, \& Mitchell, 2008; Noble \& Hanna, 2015). Companies are now morally, if not legally, obligated to negotiate impact and benefit agreements directly with Indigenous communities (Gibson \& O'Faircheallaigh, 2015; Sosa \& Keenan, 2001).

Are northern communities finally in a situation where resource development can be used to help them deal with the challenges that they face? Or are we still in a situation where mining and oil and gas developments are a source of even more problems? Researchers have pointed out that significant problems remain with modern comprehensive land claims (Kulchyski \& Bernauer, 2014; Nadasdy, 2003). Devolution of powers is problematic if the capacity to properly exercise these powers does not exist (G. White, 2009). The ability of northern communities to adequately participate in the environmental, social, and economic impact regulatory process is being questioned (Fidler \& Noble, 2013; O'Reilly, 
1996). Impact and benefit agreements are seen as problematic (Caine \& Krogman, 2010). The contention is made by some that very little has changed as far as resource development in the North is concerned (Cizek, 2005; Hall, 2013).

It was under this uncertain situation that a group of northern partners and researchers got together to develop the Resources and Sustainable Development in the Arctic (ReSDA) project in 2010. The one basic objective of this project was to find out how resource development can occur so that it provides meaningful benefits to northern communities rather than increased problems. The project was funded by the Social Sciences and Humanities Research Council (SSHRC) in 2011 and is now in its last year of funding. This special edition of the Northern Review is dedicated to presenting results from ReSDA research projects and from related projects with which ReSDA has partnered.

The first four articles deal with the possibility of benefits flowing to communities. Rodon et al. look at what increased revenue from extractive resource development means for the long-term sustainability of northern communities. After examining the various allocation strategies, they note that concerns surrounding the impacts of distribution and investment systems and the governance of the revenues, among other issues, have to be dealt with in order to ensure these benefits adequately contribute to sustainability. Hodgkins examines training and employment benefits for northern communities based on a study of the Baffinland Iron Mine and the community of Mittimatalik (Pond Inlet). He notes that the training and employment benefits that were first envisaged in the impact and benefit agreement have not met expectations and this is largely due to communications problems and larger structural governance issues. Belayneh et al. look at business development benefits associated with the Raglan mine in Nunavik, in northern Quebec, and the Voisey's Bay Mine in Labrador. While benefits do exist, they vary between regions and communities; and despite current agreements, potential benefits continue to "leak" out of the region.

While the first three articles examine benefits often traditionally thought to be some of the most important, Keske et al. look at a resource development impact, and potential benefit, rarely considered: waste management. They examine the past and current challenges of waste management in Labrador and look at future opportunities that could occur by developing more "synergistic" waste management policies for current and future resource development projects. 
The next two articles discuss questions surrounding the ability of communities to influence resource development decisions leading to community benefits, and the ways they do so. Martin and Bradshaw try to understand the importance of free, prior, and informed consent (FPIC) in mining project negotiations in regions of the North that have modern comprehensive land claims. Looking at the Yukon, they note a lack of engagement with FPIC and suggest that this is due to a number of reasons including the existence of modern treaties in that region.

The environmental assessment (EA) process is cited as an important means by which communities can ensure that negative impacts are noted and mitigated, but as Dalseg-Kennedy et al. point out in their article, gender is often given very little attention. In their examination of three projects in the Canadian North they describe the importance of including gender in EA discussions and suggest how changes can be made to improve the current situation.

The final two articles discuss issues surrounding the research that investigates the extent to which northern communities are receiving benefits from resource development. As part of the ReSDA network, Saxinger and the First Nation of the Na-Cho Nyäk Dun cooperated on a project looking at labour mobility and mining in the Yukon. The article presented here discusses the challenges and benefits of undertaking a community-based participatory research project dealing with resource development. Finally, Petrov discusses some of the issues involved with a ReSDA project undertaken in partnership with the Inuvialuit Regional Corporation. The article shows how the indicators framework developed by the Arctic Council's Arctic Social Indicators project can be applied to analyze well-being and resource development in the different regions of the Northwest Territories, and it discusses some of the limitations of this type of approach.

Most of these articles note that while benefits flow from resource development, they are not doing so to the extent they could in order to help ensure the long-term sustainability of northern communities. Results vary between projects, regions, communities, and gender. While it may be the case that communities can negotiate improved benefits more than in the past, and better mitigate potentially negative impacts, problems remain. There is a need for continued research to help northern communities maximize benefits and to enable them to decide how best to translate the short-term benefits of extractive resource development into long-term sustainable futures. 
In particular, there is a need to avoid an increase in path dependency on extractive resource development. As Dalseg-Kennedy et al. note in their article, "Presenting industrial development as the only viable form of economic development invariably involves narrowing how people conceive of both the impacts and benefits of development." It is not enough for researchers to find ways to increase benefits coming from mining and oil and gas projects. To ensure sustainable northern communities, researchers must work with communities to find innovative ways in which short-term benefits from extractive development can be used to lessen a dependence on these very activities.

\section{Guest Editor}

Chris Southcott is professor of sociology at Lakehead University, adjunct professor at Yukon College, and principal investigator of the SSHRCfunded Resources and Sustainable Development in the Canadian Arctic (ReSDA) project, 2011-2019.

\section{References}

Abele, F. (1987). Canadian contradictions: Forty years of northern political development. Arctic, 40(4), 310-320.

Alcantara, C. (2013). Negotiating the deal: Comprehensive land claims agreements in Canada. Toronto: University of Toronto Press.

Armitage, D. R. (2005). Collaborative environmental assessment in the Northwest Territories, Canada. Environmental Impact Assessment Review, 25(3), 239-258.

Berger, T. R. (1977). Northern frontier, northern homeland (Vol. 1). Ottawa: Mackenzie Valley Pipeline Inquiry.

Caine, K. J., \& Krogman, N. (2010). Powerful or just plain power-full? A power analysis of impact and benefit agreements in Canada's north. Organization $\mathcal{E}$ Environment, 23(1), 76-98.

Cameron, K., \& Campbell, A. (2009). The devolution of natural resources and Nunavut's constitutional status. Journal of Canadian Studies-Revue d'études canadiennes, 43(2), 198-219.

Cizek, P. (2005). Plundering the north for hyper-profits: Non-renewable resource extraction and royalties in the Northwest Territories 1998-2004. Yellowknife, NWT: Canadian Arctic Resources Committee.

Dacks, G. (1990). Devolution and constitutional development in the Canadian North. Ottawa: Carleton University Press. 
Diefenbaker, J. G. (1958). A new vision: Notes for a speech, Winnipeg, Feb. 12. Documents. Retrieved from http://www.canadahistory.com/sections/ documents/Primeministers/diefenbaker/docs-thenorthernvision.htm.

Fidler, C., \& Noble, B. F. (2013). Stakeholder perceptions of current planning, assessment and science initiatives in Canada's Beaufort Sea. Arctic, 66(2), 179-190.

Fitzpatrick, P., Sinclair, A. J., \& Mitchell, B. (2008). Environmental impact assessment under the Mackenzie Valley Resource Management Act: Deliberative democracy in Canada's North? Environmental Management, 42(1), 1-18.

Gibson, G., \& O'Faircheallaigh, C. (2015). IBA community toolkit: Negotiation and implementation of impact and benefit agreements (Summer 2015 ed.). Toronto: Walter \& Duncan Gordon Foundation.

Hall, R. (2013). Diamond mining in Canada's Northwest Territories: A colonial continuity. Antipode, 45(2), 376-393.

Kulchyski, P., \& Bernauer, W. (2014). Modern treaties, extraction, and imperialism in Canada's Indigenous north: Two case studies. Studies in Political Economy, 93(1), 3-24.

Lotz, J. (1970). Northern realities: The future of northern development in Canada. Toronto: New Press.

McPherson, R. (2003). New owners in their own lands: Minerals and Inuit land claims. Calgary: University of Calgary Press.

Nadasdy, P. (2003). Hunters and bureaucrats: Power, knowledge, and Aboriginal-state relations in the southwest Yukon. Vancouver: UBC Press.

Noble, B., \& Hanna, K. (2015). Environmental assessment in the Arctic: A gap analysis and research agenda. Arctic, 68(3), 341-355. https://doi.org/10.14430/ arctic4501.

O'Reilly, K. (1996). Diamond mining and the demise of environmental assessment in the north. Northern Perspectives, 24(1-4), 1-5.

Rea, K. J. (1968). The political economy of the Canadian north. Toronto: University of Toronto Press.

Saku, J. C. (2002). Modern land claim agreements and northern Canadian Aboriginal communities. World Development, 30(1), 141-151.

Sosa, I., \& Keenan, K. (2001). Impact benefit agreements between Aboriginal communities and mining companies: Their use in Canada. Ottawa: Canadian Environmental Law Association.

White, G. (2009). Governance in Nunavut: Capacity vs. culture? Journal of Canadian Studies, 43(2), 57-81.

White, G. (2009). Nunavut and the Inuvialuit Settlement Region: Differing models of northern governance. In F. Abele, T. Courchene, L. Seidle, \& F. St-Hilaire (Eds.), Northern exposure: Peoples, powers and prospects in Canada's North (pp. 283-316). Montreal: The Institute for Research on Public Policy. 